\title{
THE GRADING OF HEARING LOSS
}

\author{
Captain H. R. CABLE, M.R.C.S., L.R.C.P., R.A.M.C. \\ Lieutenant-Colonel T. M. O. MORRIS, F.R.C.S., D.L.O., R.A.M.C. \\ Cambridge Military Hospital, Aldershot
}

SUMMARY: Criteria are examined for the grading of hearing loss by pure-tone audiometry and correlating these with the gradings obtained by Free Field Voice Tests which are used in the present system of medical classification.

\section{Introduction}

The assessment of hearing loss has become increasingly sophisticated both in quantitative measurement and the qualitative spatial evaluation of the causative lesion. These advances have not been incorporated into the grading of hearing loss in Service personnel which remains based on the Free Field Voice Tests (F.F.V.Ts), as in Table I, using Conversational Voice (C.V.) amd Forced Whisper (F.W.).

Table I

The grading of hearing loss at present in use (Note: Degrees 4, 5 and 6 of the 'PULHEEMS' system of medical classification are not appropriate to the assessment of hearing)

\begin{tabular}{|c|c|c|}
\hline Category & & Criteria \\
\hline $\begin{array}{l}\text { First degree. } \\
\text { Second degree. } \\
\text { Third degree. } \\
\text { Seventh degree. } \\
\text { Eighth degree. }\end{array}$ & $\begin{array}{l}\mathrm{H} 1 \\
\mathrm{H} 2 \\
\mathrm{H} 3 \\
\mathrm{H} 7 \\
\mathrm{H} 8\end{array}$ & $\begin{array}{l}\text { F.W. heard by each ear separately at } 20 \text { feet } \\
\text { F.W. heard by each ear separately at } 10 \text { feet } \\
\text { C.V. heard by each ear separately at } 10 \text { feet } \\
\text { C.V. heard with both ears tested together at } 10 \text { feet } \\
\text { Considerable deafness sufficient to cause a man to be permanently unfit } \\
\text { for service in any capacity. }\end{array}$ \\
\hline
\end{tabular}

In practice otologists assess this grading by reference to the Pure-Tone Audiometry (P.T.A.) curves, The criteria used in this clinic are defined and compared with gradings obtained by F.F.V.Ts.

\section{Investigation}

Initially, simple guide lines were defined which were subsequently modified to give the P.T.A. outlines indicated in Table II.

Of the service patients seen and tested in this clinic during a period of six months the results from eight typical cases, when examined both by F.F.V.T. and by audiometry, are given in Table Ill.

The F.F.V.Ts were performed by one of us in a reasonably quiet treatment room measuring 21 feet by 12 feet and in the manner described in the present service pamphlet. The result was given as the distance at which more than half the test words were repeated correctly.

For the speech audiometry an Amplivox Spondiac word list recording was used with an Amplivox Model 51 audiometer and with the patient in a quiet room. The result is recorded in Table III, column 4 as the intensity above normal $(15 \mathrm{~dB})$ requiring to produce a 40 per cent score (critical level). 
Pure-tone Audiometry was performed in a sound-proof booth with a Peters Model SPD5 Audiometer in nine frequencies between $250 \mathrm{cps}$ to $8 \mathrm{~K} . \mathrm{cps}$ as seen in the audiograms at Table III, column 6. The degree of $\mathrm{H}$ at Table III, column 5 is given in accordance with the standard at Tables I and II and a complaint of deafness is recorded in column 2 of Table III.

Table II

Pure-tone audiometry outlines for grading hearing loss

\begin{tabular}{|c|c|c|}
\hline Category & \multicolumn{2}{|c|}{ Criteria } \\
\hline $\begin{array}{l}\mathrm{H} 1 \\
\mathrm{H} 2\end{array}$ & \multicolumn{2}{|c|}{$\begin{array}{l}\text { No loss greater than } 15 \mathrm{~dB} \\
\text { No loss greater than } 25 \mathrm{~dB}\end{array}$} \\
\hline \multirow[t]{2}{*}{$\mathrm{H} 2 \mathrm{~A}$} & 250 to $3000 \mathrm{cps}$ & Over $3000 \mathrm{cps}$ \\
\hline & No loss greater than $25 \mathrm{~dB}$ & $\begin{array}{l}\text { No loss greater than } 40 \mathrm{~dB} \text { at more than } \\
\text { one frequency in each ear separately. }\end{array}$ \\
\hline \multicolumn{3}{|c|}{250 to $3000 \mathrm{cps}$} \\
\hline $\mathrm{H} 3$ & \multicolumn{2}{|c|}{$\begin{array}{l}\text { Not more than two frequencies between } 30 \text { and } 40 \mathrm{~dB} \text { and not more than one greater } \\
\text { than } 40 \mathrm{~dB} \text { in each ear separately. }\end{array}$} \\
\hline $\begin{array}{l}\mathrm{H} 7 \\
\mathrm{H} 8\end{array}$ & \multicolumn{2}{|c|}{$\begin{array}{l}\text { Below standard for } \mathrm{H} 3 \text { but above } \mathrm{H} 8 \\
\text { Three or more points at } 40 \mathrm{~dB} \text { or below in each ear separately. }\end{array}$} \\
\hline
\end{tabular}

Table III

Results of eight typical cases when examined both by Free Field Voice Tests and Audiometry

\begin{tabular}{|c|c|c|c|c|c|c|c|c|c|c|c|c|}
\hline 1 & 2 & & & 3 & & & & 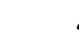 & & 5 & & 6 \\
\hline \multirow{3}{*}{ Case } & \multirow{3}{*}{$\begin{array}{l}\text { Subjective } \\
\text { deafness }\end{array}$} & \multicolumn{6}{|c|}{ F.F.V.Ts } & \multirow{2}{*}{\multicolumn{2}{|c|}{$\begin{array}{l}\text { Spcech } \\
\text { audiogram } \\
\text { critical level }\end{array}$}} & \multirow{2}{*}{\multicolumn{2}{|c|}{ Pulheems category }} & \multirow{3}{*}{$\begin{array}{l}\text { Audiogram } \\
\text { Chart number } \\
\text { (See Fig. 1) }\end{array}$} \\
\hline & & \multicolumn{3}{|c|}{ C.V. } & \multicolumn{3}{|c|}{ W.V. } & & & & & \\
\hline & & Both & $\mathbf{R t}$ & $\mathbf{L t}$ & Both & $\mathbf{R t}$ & $\mathbf{L t}$ & Rt & $\mathbf{L t}$ & F.F.V.Ts & P.T.A. & \\
\hline 1 & None & $20^{\prime}$ & $20^{\prime}$ & $20^{\prime}$ & $20^{\prime}$ & $20^{\prime}$ & $20^{\prime}$ & $\begin{array}{l}\text { No } \\
\text { loss }\end{array}$ & $\begin{array}{l}\text { No } \\
\text { loss }\end{array}$ & $\mathbf{H} 2$ & $\mathrm{H} 2$ & 1 \\
\hline 2 & None & $20^{\prime}$ & $20^{\prime}$ & $20^{\prime}$ & $20^{\prime}$ & $20^{\prime}$ & $20^{\prime}$ & $\begin{array}{l}\text { No } \\
\text { loss }\end{array}$ & $\begin{array}{l}\text { No } \\
\text { loss }\end{array}$ & $\mathrm{H} 2$ & $\mathrm{H} 2 \mathrm{~A}$ & 2 \\
\hline 3 & None & $20^{\prime}$ & $20^{\prime}$ & $20^{\prime}$ & $15^{\prime}$ & $15^{\prime}$ & $15^{\prime}$ & $\begin{array}{l}\text { No } \\
\text { loss }\end{array}$ & $\begin{array}{l}\text { No } \\
\text { loss }\end{array}$ & $\mathrm{H} 2$ & H3 & 3 \\
\hline 4 & Yes & $20^{\prime}$ & $10^{\prime}$ & $20^{\prime}$ & $20^{\prime}$ & $10^{\prime}$ & $20^{\prime}$ & $\begin{array}{l}\text { No } \\
\text { loss }\end{array}$ & $\begin{array}{l}\text { No } \\
\text { loss }\end{array}$ & $\mathrm{H} 2$ & H3 & 4 \\
\hline 5 & Yes & $15^{\prime}$ & $10^{\prime}$ & $10^{\prime}$ & $15^{\prime}$ & $10^{\prime}$ & $10^{\prime}$ & $\begin{array}{l}35 \mathrm{~dB} \\
\text { loss }\end{array}$ & $\begin{array}{l}37 \mathrm{~dB} \\
\text { loss }\end{array}$ & $\mathrm{H} 3$ & H3 & 5 \\
\hline 6 & Yes & $15^{\prime}$ & $5^{\prime}$ & $15^{\prime}$ & $15^{\prime}$ & $5^{\prime}$ & $15^{\prime}$ & $\begin{array}{l}30 \mathrm{~dB} \\
\text { loss }\end{array}$ & $\begin{array}{l}30 \mathrm{~dB} \\
\text { loss }\end{array}$ & $\mathrm{H} 7$ & H3 & 6 \\
\hline 7 & Yes & $5^{\prime}$ & $5^{\prime}$ & $5^{\prime}$ & $2^{\prime}$ & $2^{\prime}$ & $2^{\prime}$ & $10 \mathrm{~dB}$ & $10 \mathrm{~dB}$ & H8 & $\mathrm{H} 8$ & 7 \\
\hline 8 & Yes & $2^{\prime}$ & $2^{\prime}$ & $2^{\prime}$ & $2^{\prime}$ & $2^{\prime}$ & $2 !$ & $\begin{array}{l}27 \mathrm{~dB} \\
\text { loss }\end{array}$ & $\begin{array}{l}18 \mathrm{~dB} \\
\text { loss }\end{array}$ & H8 & H8 & 8 \\
\hline
\end{tabular}



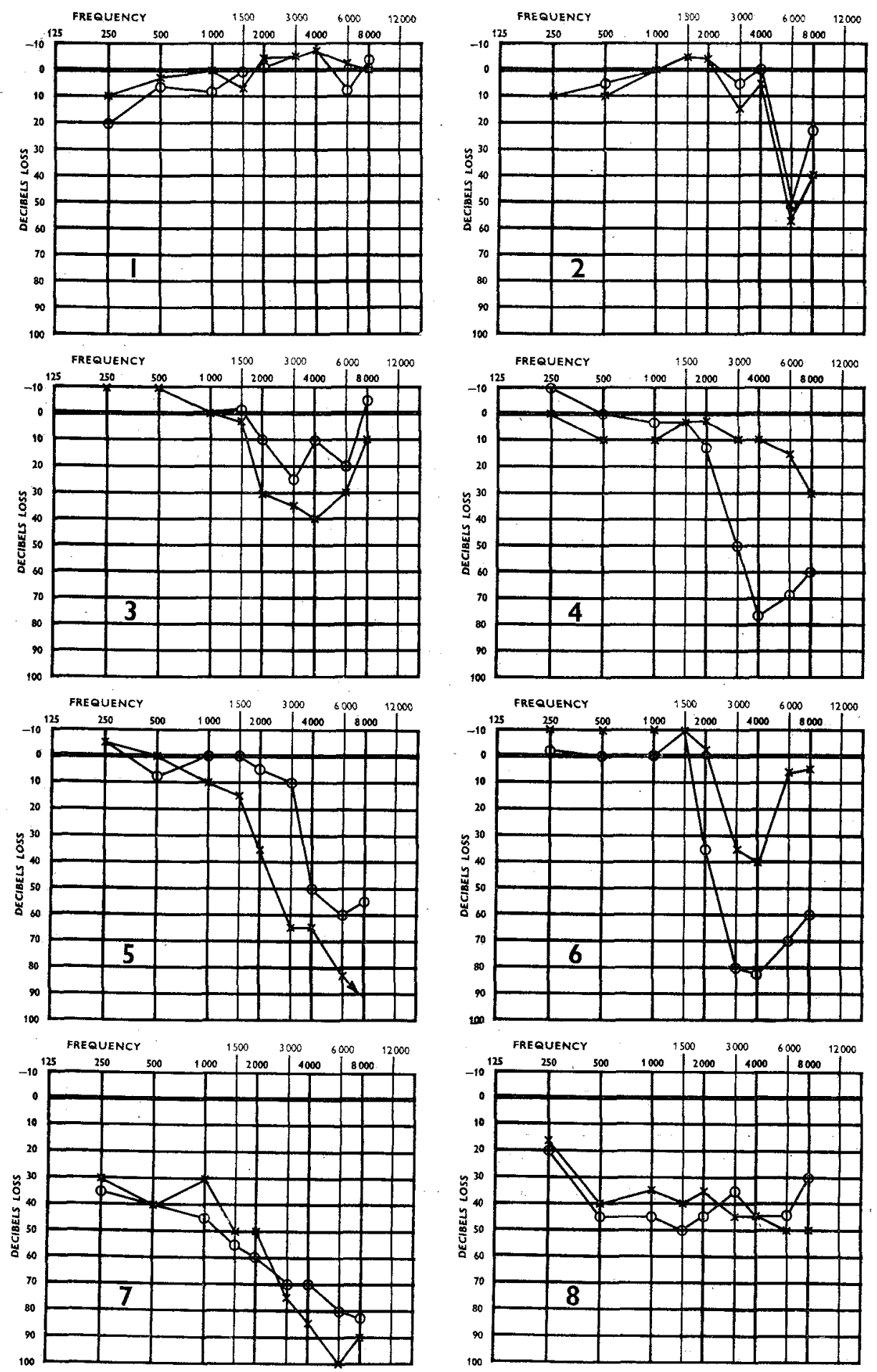

Fig. 1. Results of eight typical cases when examined both by Free Field Voice Tests and Audiometry. O-O left ear. 


\section{Discussion}

The F.F.V.Ts have the advantage of requiring no apparatus and of being a good functional test of auditory discrimination for unamplified speech. When performed carefully the whispered voice test can reveal a high-tone loss but this is uncertain and provides only a very approximate quantitative measure. The most important disadvantage is the impossibility of standardisation between different examiners and even for the same examiner on different occasions. A room at least 20 feet long is required with low ambient noise and there is a considerable subjective element in the responses. It is of little value in an audiological clinic owing to this impossibility of standardisation and its inaccuracy as a quantitative measurement of small changes in hearing loss.

Pure-tone Audiometry has the over-riding advantage of being a standardised test which can be repeated within a small margin of error by different examiners at different times. In addition the threshold assessment can be confirmed objectively by impedence audiometry. It has the disadvantages of requiring special apparatus and being only indirectly related in function. Where this apparatus is available it is the most reliable test on which the classification of the degree of hearing loss can be based.

Speech audiometry gives in many respects, less information than P.T.A. and requires more time and equipment to perform but it is more related to function.

The many variables in the P.T.A. curve and the subject make the definition of degrees of hearing loss a difficult task and rigid adherence to any such scheme unwise. There may be low-tone loss without high-tone loss or vice versa; speech discrimination may be considerably worse for a given P.T.A. loss in a sensori-neural perceptive deafness than in a conductive loss owing to the recruitment phenomenon which causes distortion of sound.

Criteria, like those given in Table II, can only be considered as approximate guides; there will be many border-line cases in which such factors as intelligence, training and employment will be considered. In these cases the F.F.V.Ts and speech audiometry will still be important as additional evidence.

The most common grading of hearing loss in general use is probably that of Beasley (1940) and is given in Table IV. This was based on social disability and its correlation

Table IV

Summary of Beasley grades and the approximate corresponding degrees of $\mathbf{H}$.

\begin{tabular}{c|l|c|c}
\hline Grade & \multicolumn{1}{|c|}{ Social disability } & Speech audiogram & $\begin{array}{c}\text { Corresponding } \\
\text { degree of } \mathrm{H}\end{array}$ \\
\hline I & For long distance speech such as a lecturer & $18-33 \mathrm{~dB}$ loss & 3 \\
\hline II & $\begin{array}{l}\text { For tete-a-tete conversation at } 3 \text { feet in } \\
\text { addition to above }\end{array}$ & $34-37 \mathrm{~dB}$ loss & 7 \\
\hline III & $\begin{array}{l}\text { For loud conversation and telephone in } \\
\text { addition to I and II }\end{array}$ & $47 \mathrm{~dB}$ loss & 8 \\
\hline
\end{tabular}

with speech audiometry is shown. Social disability and speech audiometry do not provide such a good basis for service grading as P.T.A. particularly because the latter reveals high-tone loss at an early stage and allows finer gradation of categories. 
The first three gradings in Table II are 'normal' gradings. At $25 \mathrm{~dB}$ loss there is little detectable reduction in speech discrimination although the $20 \mathrm{~dB}$ level is a more widely accepted lower limit for normal hearing. The level of $0 \mathrm{~dB}$ represents a sound pressure of 0/00024 dynes per sq $\mathrm{cm}$ (British Standard) and represents an average intensity at the various frequencies of the hearing threshold measured in a group of subjects with normal hearing. This level could not be used as a criterion for normal hearing in Service grading as it is unnecessarily severe and relates to the threshold rather than function.

Normal hearing implies the ability to appreciate and recognize the meaning of sounds and words. For a ' tooth-arm ' soldier the former must include such high frequency sounds as rustling undergrowth and the snapping of a twig. The correlation of high-tone loss with this functional aspect has not been attempted in this clinic. The recognition of early high-tone loss is important as part of a hearing conservation programme; although initially there may be no functional loss, continued exposure to high intensity noise will increase the hearing loss to such a degree as to produce functional loss.

The majority of speech sounds lie within the 250 to $3000 \mathrm{cps}$ range with few extending to $4000 \mathrm{cps}$ and above. When all frequencies above $3000 \mathrm{cps}$ are entirely cut out there is a 15 per cent loss of speech intelligibility and if those above $1500 \mathrm{cps}$ are similarly cut out there is a 35 per cent loss (Whetnall, 1952).

As a comparison, the standard of hearing for acceptance as a civil air pilot allows a hearing loss of $40 \mathrm{~dB}$ at $4000 \mathrm{cps}$ (Board of Trade).

The category $\mathrm{H} 2 \mathrm{~A}$ is suggested in Table II to recognise the presence of high-tone loss which is not producing a clinically detectable functional loss but requires the subject to have regular audiometry. In this way there is surveillance of those who may be particularly sensitive to noise.

The intervals at which audiometry is carried out will depend on circumstances. A recruit undergoing training might require audiometry at three-monthly intervals or less; an infantry man six-monthly and for a non-combatant only rarely exposed to high intensity noise, annually. It may be that personnel in this category should not serve in a ' tooth-arm' but in view of the high incidence of this type of deafness such exclusion, on present evidence, is likely to be neither necessary nor practical.

In category $\mathrm{H} 3$ there is a definite functional loss for speech discrimination and the subjects will complain of deafness. Personnel in this category are employed in nonbatant roles so that their functional loss only to speech need be considered and the high tones may be ignored.

All those having a hearing loss below $\mathrm{H} 3$ but above $\mathrm{H} 8$ are placed in category $\mathrm{H} 7$.

In category $\mathrm{H} 8$ most subjects would require a hearing aid. It is in the recording of this category that most thought is required in the assessment of hearing loss in relation to other factors previously mentioned.

In the examples given at Table III the close correlation between the criteria of Tables I and II can be seen except in Cases 3 and 4 where high-tone loss is present. There is a functional loss to F.F.V.Ts but not sufficient to reduce the category. This degree of high-tone loss does reduce the efficiency of a soldier and should be recognised in grading. It may be that the standard of hearing required for certain employments could be reduced in view of the greater accuracy and discrimination of modern hearing tests. It is preferable to alter the employment standard in this way rather than extend the criteria for ' normal' hearing. 
It may be somewhat surprising that in Cases 5 and 6 there are such poor scores on speech audiometry: this is particularly so in Case 5 and they illustrate the poor response to amplification in neuro-sensory perceptive deafness. The hearing loss in Case 5 is thought to be due to a combination of Menière's disease and acoustic trauma; in Case 6 the hearing loss is likely to be due to acoustic trauma. The poor score of Case 6 on F.F.V.Ts on the right side will also be noted which results from the almost complete loss of frequencies above $1500 \mathrm{cps}$ and illustrates the effect of removing these frequencies as previously noted. In addition, it will be seen that the P.T.A. category is higher than that given by F.F.V.Ts and may be more realistic in view of the hearing at 15 feet (column 3).

Table II has been used in this clinic with only one difference; that category $\mathrm{H} 2 \mathrm{~A}$ is not officially recognised. Subjects with a hearing loss corresponding to this grading are made $\mathrm{H} 2$ and a recommendation for regular audiometry is written in the medical documents.

The criteria are relatively simple and with the exception of $\mathrm{H} 3$ require little effort to understand and memorise. Although their application must remain flexible their definition if accepted could result in a more standardised approach to the grading of the service man's hearing from pure-tone audiometry.

\section{REFERENCES}

BeAsley, W. C. (1940). Laryngoscope (St. Louis) 50, 586.

Whetnal, Edith (1952). In Diseases of the Ear, Nose and Throat. Volume 2, Chapter 16. Butterworths, London.

Preliminary Announcement-Corps Occasions for 1971

\section{Provisional dates are as follows:-}

R.A.M.C. Annual General Meetings of General and Officers Funds, R.A.M.C. Association and Corps Mess Fund

30 April

Army Medical Services Swimming Gala

R.A.M.C. Officers' Dinner (7-15 for 8 p.m.)

R.A.M.C. Officers' ' At Home ' (4-6 p:m.)

R.A.M.C./R.A.D.C. Sports

Army Medical Services Drumhead Service at R.A.M.C. Training Centre and R.A.M.C. Association Annual Lunch

R.A.M.C. Golfing Society-Spring Meeting-Worplesden Golf Club Summer Meeting-North Hants Golf Club Autumn Meeting-West Hill Golf Club

R.A.M.C. (Q.M. Adm. \& Tech.) Officers' Dinner Club 